\title{
GTF2I Mutations Are Common in Thymic Epithelial Tumors But Not in Hematological Malignancies
}

\author{
GIULIA TARRINI ${ }^{1}$, ELENA CIABATTI ${ }^{1}$, SIMONE PACINI $^{1}$, SARA GALIMBERTI $^{1}$ and IACOPO PETRINI ${ }^{2}$ \\ ${ }^{1}$ Section of Hematology, Department of Clinical and Experimental Medicine, \\ and ${ }^{2}$ General Pathology, Department of Translational Research and New Technologies in Medicine and Surgery, \\ University of Pisa, Pisa, Italy
}

\begin{abstract}
Background: Mutation of general transcription factor IIi (GTF2I) (chromosome 7 c.74146970T>A) is common in thymic epithelial tumors and is a candidate driver aberration for cancer growth. To our knowledge, this mutation has not been described in other diseases. We evaluated the presence of GTF2I mutation in hematological malignancies. Materials and Methods: We sequenced samples from 31 patients with acute leukemia, 29 with chronic leukemia and 12 with myelodysplastic syndrome. The genomic fragment of exon 15 containing the hotspot of mutation was amplified using polymerase chain reaction $(P C R)$ and sequenced. Results: We did not identify any GTF2I mutation in patients with hematological malignancies. Conclusion: Even though our sample size was limited, our data and reports from the literature suggest that GTF2I mutation is not present or is uncommon in these diseases.
\end{abstract}

General transcription factor IIi $(G T F 2 I)$ is a gene located on the long arm of chromosome 7 (7q11.23) and encodes for a transcription factor that regulates the expression of genes important for cell cycle and the development of Blymphocytes (1). Copy-number aberrations of GTF2I are observed in Williams-Beuren and Somerville-van der Aa syndromes (2).

Recently, our group identified a new missense mutation (c.74146970T>A) of GTF2I in thymic epithelial tumors (3). This mutation is somatic and alters protein structure and function, according to predictive algorithms (SIFT (4) (http://sift.jcvi.org) and Polyphen 2 (5) (http://genetics.bwh. harvard.edu/pph2/). In vitro, GTF2I mutation does not induce anchorage-independent growth but accelerates cell proliferation

Correspondence to: Iacopo Petrini, MD, Ph.D., General Pathology, University of Pisa, Via Savi 10, Pisa, 56121, Italy. Tel: +39 0502212571, Fax: +39 050993378, e-mail: iacopo.petrini@unipi.it

Key Words: GTF2I, thymoma, leukemia.
(3). Thymic epithelial tumors are classified into thymomas and thymic carcinomas. Thymomas are further divided into $\mathrm{A}, \mathrm{AB}$, $\mathrm{B} 1, \mathrm{~B} 2$, and $\mathrm{B} 3$ histotypes (6). GTF2I mutation is common in $\mathrm{A}$ and $\mathrm{AB}$ thymomas ( $82 \%$ and $74 \%$, respectively). The mutation frequency progressively decreases in B1, B2, B3 thymomas and thymic carcinoma. Types $\mathrm{A}$ and $\mathrm{AB}$ present the best prognosis and indeed the presence of the GTF2I mutation is a favorable prognostic marker in patients with thymic epithelial tumors (3).

In peripheral T-cell lymphoma, Vallois and coworkers described six different missense GTF2I mutations, which gain of function possibly activates the AP1 transcription factor/mitogen-activated protein kinase (MAPK) pathway pathway (7). Moreover, a translocation involving GTF2I and retinoid acid receptor alpha $(R A R A)$ has been described in a case of retinoic acid-resistant acute promyelocytic leukemia (8). No further data about the involvement of GTF2I in other hematological malignancies are available.

The research of somatic mutations using whole and exome sequencing in the genome of different kinds of cancer did not show any GTF2I mutation in the position c.74146970T>A, according to The Cancer Genome Atlas (TCGA) and COSMIC database. However, the presence of the pseudogenes, GTF2IPI and GTF2IP4, could be a confounding factor because they share a very similar sequence with the mutation's locus. Therefore, the most common algorithms used to call a somatic mutation can be flawed and GTF2I mutations might be misdiagnosed.

We decided to investigate if the GTF2I mutation (c.74146970T>A) is present in acute and chronic leukemia, whose behavior is often very different, either indolent or very aggressive, similarly to that observed in thymic epithelial tumors. Moreover, because the GTF2I gene is involved in the Bruton kinase (BTK) pathway (1), particular attention has been paid to chronic lymphocytic leukemia, where BTK is hyper-activated, as well demonstrated in the clinical setting by the efficacy of its inhibitor, ibrutinib (9). 


\section{Materials and Methods}

Blood and bone marrow samples were collected at the Hematology Care Unit of the University of Pisa during the regular clinical practice. All patients signed an informed consent form whereby they agreed to donate their surpIus tissue for further scientific purposes; this consent form was approved by the Ethical Office of the Azienda Ospedaliero-Universitaria Pisana.

Blood and bone marrow samples were extracted with the EZ1 SPD DNA blood Kit version 3 according to the manufacturer's protocol (Qiagen, Valencia, CA, USA) via automated EZ1 Advanced QIAGEN extractor. Three hundred and fifty microliters of samples were used. DNA quality and concentration was measured using a Nanodrop 2000 Spectrophotometer (Thermo Fisher Scientific, Wilmington, DE, USA).

Polymerase chain reaction (PCR) amplification was performed using PCR Reagent System kit (Invitrogen) and 200 $\mathrm{ng}$ of DNA. The sequence of forward and reverse primers GTF2I (upper-case) attached to M13 sequence (lower-case) was tgtaaaacgacggccagtA TCCCGTACCCTCTTTTCC, and caggaaacagctatgaccAGACAA GAGTTCAACAGG, respectively. The 3' end of the forward primer corresponds to a nucleotide present in the gene but not in the pseudogene sequences. Cycling was performed at $94^{\circ} \mathrm{C}$ for $3 \mathrm{~min} ; 35$ cycles at $94^{\circ} \mathrm{C}$ for $15 \mathrm{sec}, 62.5^{\circ} \mathrm{C}$ for $15 \mathrm{sec}, 72^{\circ} \mathrm{C}$ for $30 \mathrm{sec} ; 72^{\circ} \mathrm{C}$ for $7 \mathrm{~min}$; and a hold at $4^{\circ} \mathrm{C}$. Cycling parameters were optimized to amplify GTF2I but not pseudogene sequences (3).

The PCR products were purified using Exosap (USB, Cleveland, OH, USA) and then treated using BigDye Terminator v1.1 cycle sequencing kit (Applied Biosystems, Foster City, CA, USA). The excess dye terminator was removed using Centri Sep spin columns (Applied Biosystems) and the products were analyzed on an automated DNA sequencer (ABI PRISM 3100 Genetic Analyzer; Applied Biosystems) using forward and reverse M13 primers.

\section{Results}

Seventy-two patients were evaluated for the presence of the GTF2I c.74146970T>A mutation (patient characteristics are summarized in Table I).

The median age was 66 (range $=20-87$ ) years. Twentythree patients were affected by acute myeloid leukemia (AML), eight by acute lymphoblastic leukemia (ALL), 18 by chronic lymphoid leukemia (CLL), 11 by chronic myeloid leukemia (CML), and 12 by myelodysplastic syndromes (MDS). All samples were harvested at diagnosis, in order to ensure a good representativeness of the neoplastic cells in the sample (mean number of neoplastic infiltration in ALL and CLL $=80 \%$ ). Tumor DNA was extracted from peripheral blood of two patients with CML and 10 with CLL and from bone marrow of the remaining patients.

Notwithstanding the heterogeneity of the considered diseases, no samples showed the GTF2I (c.74146970T>A) mutation. On the contrary, the presence of GTF2I mutation was shown in our positive control, a type A thymoma (Figure 1).
Table I. Summary of clinical characteristics of patients included in this study.

\begin{tabular}{lccccc}
\hline Disease & $\begin{array}{c}\text { Patients, } \\
\mathrm{n}\end{array}$ & $\begin{array}{c}\text { Median age, } \\
\text { years }\end{array}$ & $\begin{array}{c}\text { BM/PB } \\
\text { samples, } \mathrm{n}\end{array}$ & $\begin{array}{c}\text { Cancer } \\
\text { cells }\end{array}$ & $\begin{array}{c}\text { GTF2I } \\
\text { status }\end{array}$ \\
\hline AML & 23 & 54 & $23 / 0$ & $76 \%$ & WT \\
ALL & 8 & 41 & $8 / 0$ & $81 \%$ & WT \\
CLL & 18 & 66 & $16 / 2$ & $80 \%$ & WT \\
CML & 11 & 69 & $1 / 10$ & nm & WT \\
MDS & 12 & 80 & $12 / 0$ & nm & WT \\
\hline
\end{tabular}

AML: Acute myeloid leukemia; ALL: acute lymphoblastic leukemia; CLL: chronic lymphoid leukemia; CML: chronic myeloid leukemia; MDS: myelodysplastic syndromes; WT wild-type; BM: sample from bone marrow; PB: sample from peripheral blood; nm: not measurable.

\section{Discussion}

In our series of five different hematological diseases, the GTF2I c.74146970T $>$ A mutation was not detected; this supports our previous observation and confirms that this mutation seems to be a specific aberration of thymic epithelial tumors.

GTF2I is a transcription factor that can bind the E-box and the initiator element (Inr) of gene promoters (10). GTF2I coordinates the formation of a protein complex necessary for the assembly of the basal transcription machinery. GTF2I binds to the promoter of genes such as $c-F O S$, and promotes cell proliferation (11). Moreover, GTF2I can be phosphorylated by intracellular tyrosine kinases such as BTK and the serum-response elements (12). This kind of regulation allows GTF2I to promote transcription in response to cellular stimuli, including those that control cell proliferation (10). Therefore, GTF2I is a candidate cancer gene. Indeed, its mutation (c.74146970T>A) increases the intracellular levels of GTF2I protein, reducing its degradation, and accelerated cell proliferation in some in vitro models (3).

Fusion genes including GTF2I and nuclear receptor coactivator 2 (NCOA2) or RARA partners have been described in angiofibroma of soft tissues and promyelocytic leukemia, respectively $(8,13)$. In angiofibroma the fusion product included the site of mutation (chromosome 7 c.74146970T $>\mathrm{A}$ ); on the contrary, in promyelocytic leukemia, the sequence of the GTF2I gene was truncated after its first repeat.

In 2014, Lawrence and colleagues performed a combined analysis of TCGA reports and identified occasional somatic mutations of GTF2I across 21 tumor types, including breast, colorectal, lung and endometrial cancer (14). However, these somatic mutations were not recurrent and did not affect the same site of mutation observed in thymic epithelial tumors. 


\section{Thymoma A with GTF2I mutation}

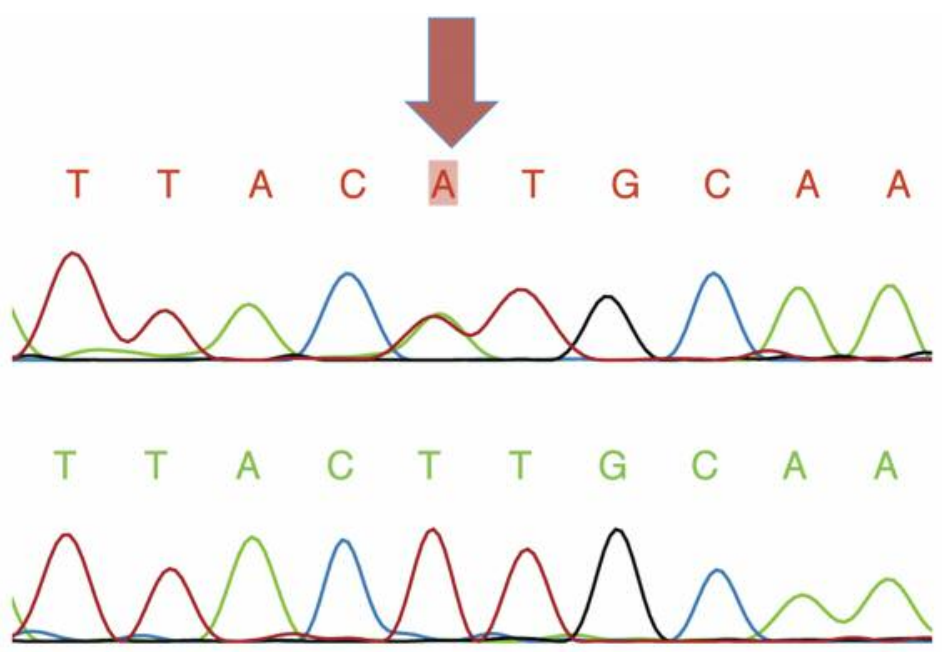

\section{AML without GTF2 mutation}

Figure 1. Positive control comprising of a type A thymoma with general transcription factor IIi (GTF2I) mutation T/A and an example of wild-type patient with acute myeloid leukemia (AML).

Therefore, it is difficult to believe that they represent driver mutations for these tumor types.

In 2016, GTF2I mutations were observed in $6 \%$ of angioimmunoblastic T-cell lymphomas evaluated with a deep sequencing panel of genes selected on the basis of their involvement in T-cell receptor signaling (7). None of these mutations involved the same amino acid residue of TFII-I nor the residue mutated in thymic epithelial tumors. The authors concluded that these GTF2I mutations are likely to be activating as those reported in thymic epithelial tumors (7).

Our sample set was limited in order to demonstrate clearly the absence of the c.74146970T>A GTF2I mutation in leukemia and MDS. The sample size of a cohort of patients that is sufficient to exclude the presence of a mutation depends on the frequency of that mutation and the overall frequency of mutations of that kind of tumor. For example, AML and CLL present a median of 0.4 and 0.6 mutations per million base pairs of DNA (14); in order to exclude the presence of a mutation present in $10 \%$ of patients with a statistical power of $80 \%, 60$ and 70 patients, respectively, would be needed (14).

Our data and previous exome sequencing results support the absence of the c.74146970T>A mutation in ALL and CLL. Our analysis focused on a particular location of the gene but the presence of other mutations, similar to those observed in lymphomas, cannot be excluded.

\section{Acknowledgements}

This article was funded using PE-2011-02348507 grant.

\section{References}

1 Sacristan C, Tussie-Luna MI, Logan SM and Roy AL: Mechanism of Bruton's tyrosine kinase-mediated recruitment and regulation of TFII-I.J Biol Chem 279: 7147-7158, 2004.

2 Adamo A, Atashpaz S, Germain PL, Zanella M, D'Agostino G, Albertin V, Chenoweth J, Micale L, Fusco C, Unger C, Augello B, Palumbo O, Hamilton B, Carella M, Donti E, Pruneri G, Selicorni A, Biamino E, Prontera P, McKay R, Merla G and Testa G: 7q11.23 Dosage-dependent dysregulation in human pluripotent stem cells affects transcriptional programs in disease-relevant lineages. Nat Genet 47: 132-141, 2015.

3 Petrini I, Meltzer PS, Kim IK, Lucchi M, Park KS, Fontanini G, Gao J, Zucali PA, Calabrese F, Favaretto A, Rea F, RodriguezCanales J, Walker RL, Pineda M, Zhu YJ, Lau C, Killian KJ, Bilke S, Voeller D, Dakshanamurthy S, Wang Y and Giaccone G: A specific missense mutation in GTF2I occurs at high frequency in thymic epithelial tumors. Nat Genet 46: 844-849, 2014.

4 Kumar P, Henikoff S and Ng PC: Predicting the effects of coding non-synonymous variants on protein function using the SIFT algorithm. Nat Protoc 4: 1073-1081, 2009.

5 Adzhubei IA, Schmidt S, Peshkin L, Ramensky VE, Gerasimova A, Bork P, Kondrashov AS and Sunyaev SR: A method and server for predicting damaging missense mutations. Nat Meth 7: 248-249, 2010

6 Travis WD, Brambilla E, Nicholson AG, Yatabe Y, Austin JH, Beasley MB, Chirieac LR, Dacic S, Duhig E, Flieder DB, Geisinger K, Hirsch FR, Ishikawa Y, Kerr KM, Noguchi M, Pelosi G, Powell CA, Tsao MS, Wistuba I and Panel WHO: The 2015 World Health Organization Classification of Lung Tumors: Impact of genetic, clinical and radiologic advances since the 2004 classification. J Thorac Oncol 10: 1243-1260, 2015 . 
7 Vallois D, Dobay MP, Morin RD, Lemonnier F, Missiaglia E, Juilland M, Iwaszkiewicz J, Fataccioli V, Bisig B, Roberti A, Grewal J, Bruneau J, Fabiani B, Martin A, Bonnet C, Michielin O, Jais JP, Figeac M, Bernard OA, Delorenzi M, Haioun C, Tournilhac O, Thome M, Gascoyne RD, Gaulard P and de Leval L: Activating mutations in genes related to TCR signaling in angioimmunoblastic and other follicular helper T-cell-derived lymphomas. Blood 128: 1490-1502, 2016.

8 Li J, Zhong HY, Zhang Y, Xiao L, Bai LH, Liu SF, Zhou GB and Zhang GS: GTF2I-RARA is a novel fusion transcript in a $\mathrm{t}(7 ; 17)$ variant of acute promyelocytic leukaemia with clinical resistance to retinoic acid. Br J Haematol 168: 904-908, 2015.

9 Deeks ED: Ibrutinib: A review in chronic lymphocytic leukaemia. Drugs 77: 225-236, 2017.

10 Roy AL: Biochemistry and biology of the inducible multifunctional transcription factor TFII-I. Gene 274: 1-13, 2001.

11 Grueneberg DA, Henry RW, Brauer A, Novina CD, Cheriyath V, Roy AL and Gilman M: A multifunctional DNA-binding protein that promotes the formation of serum response factor/ homeodomain complexes: identity to TFII-I. Gene Dev 11: 2482-2493, 1997.
12 Egloff AM and Desiderio S: Identification of phosphorylation sites for Bruton's tyrosine kinase within the transcriptional regulator BAP/TFII-I. J Biol Chem 276: 27806-27815, 2001.

13 Arbajian E, Magnusson L, Mertens F, Domanski HA, Vult von Steyern F and Nord KH: A novel GTF2I/NCOA2 fusion gene emphasizes the role of $N C O A 2$ in soft tissue angiofibroma development. Gene Chromosome Cancer 52: 330-331, 2013.

14 Lawrence MS, Stojanov P, Mermel CH, Robinson JT, Garraway LA, Golub TR, Meyerson M, Gabriel SB, Lander ES and Getz G: Discovery and saturation analysis of cancer genes across 21 tumour types. Nature 505: 495-501, 2014.

Received August 4, 2017

Revised August 27, 2017

Accepted August 28, 2017 